ISBN 978-93-84468-94-1

International Conference on Education, Business and Management (ICEBM-2017)

Bali (Indonesia) Jan. 8-9, 2017

\title{
An Experiment of Heat Exchanger Produces Hot Water Using Waste Heat Recovery from Air Conditioning
}

\author{
Kosart Thawichsri ${ }^{1}$, Piyawat Sitipasa ${ }^{2}$, Tomon Sitiwong ${ }^{3}$ and Thitison Pedawankut ${ }^{4}$ \\ ${ }^{1,2,3,4}$ Energy Engineering Department, Siam Technology College, Bangkok, Thailand. \\ ${ }^{1}$ Email: kosartpikpik@yahoo.com.sg
}

\begin{abstract}
This paper is a Experiment of Heat Exchanger Produces hot water Using Waste Heat Recovery from Air Conditioning. Its objective is to compare the efficiency of heat exchanger produces hot Using Waste Heat Recovery water from the air conditioning and compare the Coefficient of Performance (COP) of the air conditioning. The experiment is separated into two sections. The first section is the operation of air conditioning and the second section is Heat Exchanger producing hot water incorporated with waste heat recovery from air conditioning. The study reveals that the COP of the first section is 3. Meanwhile, the COP of the second section is 5 and the maximum temperature of hot water incorporated with waste heat recovery from air conditioning is $65^{\circ} \mathrm{C}$ with $3 \mathrm{~L} / \mathrm{min}$ of water flow rate. This flow rate through heat exchanger is the most efficient in the experiments on hot water production. In comparison with the first section, can save more than $38 \%$ of energy.
\end{abstract}

Keywords: air conditioning, heat exchanger, hot water, waste heat recovery

\section{Nomenclature}

$\mathrm{q}_{\mathrm{H}} \quad$ heat transfer at moment $[\mathrm{W}]$

$\dot{m}$ mass flow rate $[\mathrm{kg} / \mathrm{s}]$

$\mathrm{C}_{\mathrm{p}}$ specific heat capacity $[\mathrm{kJ} / \mathrm{kg} \mathrm{K}]$

$\mathrm{T}_{\text {in }} \quad$ temperature inlet $[\mathrm{K}]$

$\mathrm{T}_{\text {out }}$ temperature outlet $[\mathrm{K}]$

$\eta_{\mathrm{t}} \quad$ the collector efficiency [\%]

$\mathrm{I}_{\mathrm{t}}$ solar radiation $\left[\mathrm{W} / \mathrm{m}^{2}\right]$

$\mathrm{A}_{\mathrm{C}} \quad$ collector of area $\left[\mathrm{m}^{2}\right]$

$F_{R}$ the collec heat removal factor

$(\tau \alpha)_{n}$ the multiple reflection of diffuse radiation continues

$\mathrm{U}_{\mathrm{L}}$ the product of a heat transfer coefficient $\left[\mathrm{W} / \mathrm{m}^{2} . \mathrm{K}\right]$

$\mathrm{T}_{\mathrm{i}} \quad$ temperature inlet [K]

$\mathrm{T}_{\mathrm{a}} \quad$ ambient temperature $[\mathrm{K}]$

$\mathrm{I}_{\mathrm{T}} \quad$ the critical radiation level $\left[\mathrm{W} / \mathrm{m}^{2} . \mathrm{K}\right]$

$\mathrm{Q}_{\mathrm{U}}$ the usefut energy [W]

$\dot{m}$ mass flow rate $[\mathrm{kg} / \mathrm{s}]$

$\mathrm{C}_{\mathrm{p}} \quad$ specific heat capacity $[\mathrm{kJ} / \mathrm{kg} \mathrm{K}]$

$\mathrm{T}_{\mathrm{o}}$ temperature outlet $[\mathrm{K}]$

$\dot{W}_{-} \quad$ Power of compression $[\mathrm{kW}]$

$\mathrm{h}_{1} \quad$ Specific enthalpy at the inlet state $[\mathrm{kJ} / \mathrm{kg}]$ 
$\mathrm{h}_{2} \quad$ Specific enthalpy at the exit state $[\mathrm{kJ} / \mathrm{kg}]$

$\dot{m}_{R} \quad$ The mass flow rate of refrigerant $[\mathrm{kg} / \mathrm{s}]$

$\dot{Q}_{\operatorname{Lim} o}$ The rate of heat absorption in an evaporator $[\mathrm{kW}]$

$\mathrm{h}_{4} \quad$ Specific enthalpy at the inlet state $[\mathrm{kJ} / \mathrm{kg}]$

$\mathrm{h}_{1} \quad$ Specific enthalpy at the exit state $[\mathrm{kJ} / \mathrm{kg}]$

\section{Introduction}

Hospital are considered as large energy consumers for a variety of activities. In Thailand, $50 \%$ of electrical energy is consumed by air condition system, $30 \%$ of electrical energy is consumed by lighting system and the rest is used to produce hot water. [1] Hover the electric energy is not a good energy source to produce the hot water. In the mean time, such a great deal of waste heat is rejected by the air-condition system. If the waste heat recovery from air conditioning is used to produce hot water the energy consumption should be reduced. According to the study, it is found that the hot water production system using heat recovery from air condition can promote energy saving as well as reduce the global warming situation. However, in Thailand especially in hospital, and hotel, the operation of air condition which causes much more waste heat energy. [2], [3]

The objective of An Experiment of Heat Exchanger Produces Hot Water from Air Conditioning is to study on the temperature of hot water in storage tank as well as to study on the ability to save energy of Air Conditioning. Therefore, the research aims at the development of Heat Exchanger Produces Hot Water from Air Conditioning and the increase of air conditioning's efficiency.

\section{Theory}

The actual heat transfer may be computes by calculating either the energy lost by hot fluid or the energy or the cold fluid, as show in equation (1). [4], [5]

$$
q_{H}=\dot{m} C_{p}\left(T_{\text {in }}-T_{\text {out }}\right)
$$

Where, $\quad q_{H}=$ heat transfer at moment, $\mathrm{W}$

$\dot{m}=$ mass flow rate, $\mathrm{kg} / \mathrm{s}$

$C_{p}=$ specific heat capacity, $\mathrm{kJ} / \mathrm{kg} \mathrm{K}$

$T_{\text {in }}=$ temperature inlet, $\mathrm{K}$

$T_{\text {out }}=$ temperature outlet, $\mathrm{K}$

The ideal vapor-compression refrigeration cycle

Air conditioner comprise of four parts as follows: compressor, condenser, expansion valve and evaporator. These four parts make up the circuit though which the refrigerant travels. Copper tube carries the refrigerant to each of the major components. One of the very useful properties of the refrigerant is the pressure-temperature relationship of the saturated vapor. A refrigerant vapor is said to be saturated whenever both liquid and vapor are present in the same container, in stable equilibrium. Under these conditions a fixed relationship exists between the temperature of the refrigerant in the container and its pressure. Diagram frequently used in the analysis of vapor-compression refrigeration cycle is the P-h diagram, as shown in Fig.1. On this diagram, the heat transfer in the condenser and the evaporator is portion to the lengths of the corresponding process curves. The vaporcompression refrigeration cycle is the most widely used cycle for refrigerators, air-condition systems. [4], [6] 


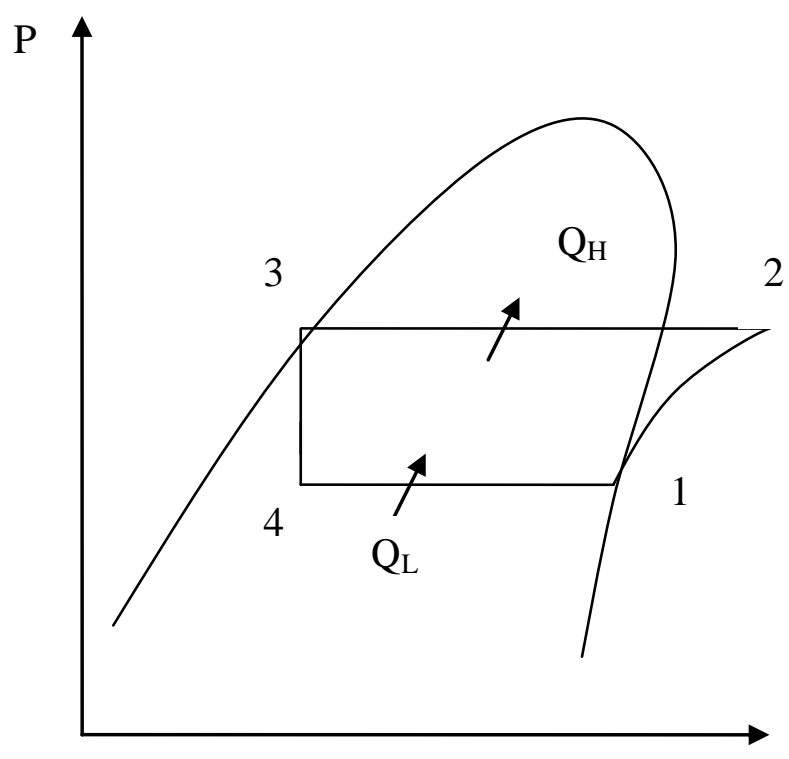

Fig.1. P-h diagram of the refrigeration cycle

An air-conditioning system consists of processes:

1-2 Isentropic compression in compressor

$$
\dot{W}_{12}=\dot{W}_{C}=\dot{m}_{R}\left(h_{2}-h_{1}\right)
$$

where $\quad \dot{W}_{12}=\dot{W}_{C}=$ Power of compression, $\mathrm{kW}$

$h_{l} \quad=$ Specific enthalpy at the inlet state, $\mathrm{kJ} / \mathrm{kg}$

$h_{2} \quad=$ Specific enthalpy at the exit state, $\mathrm{kJ} / \mathrm{kg}$

$\dot{m}_{R}=$ The mass flow rate of refrigerant, $\mathrm{kg} / \mathrm{s}$

2-3 Constant pressure heat rejection in condenser

$$
\dot{Q}_{23}=\dot{Q}_{\text {Cond }}=\dot{m}_{R}\left(h_{2}-h_{3}\right)
$$

Where $\quad \dot{Q}_{23}=\dot{Q}_{\text {Cond }}=$ The rate of heat rejection at condenser, $\mathrm{kW}$

$h_{2}=$ Specific enthalpy at the inlet state, $\mathrm{kJ} / \mathrm{kg}$

$h_{3}=$ Specific enthalpy at the exit state, $\mathrm{kJ} / \mathrm{kg}$

3-4 Throttling in an expansion device

$$
h_{3}=h_{4}
$$

Where $\quad h_{3}=$ Specific enthalpy at the inlet state, $\mathrm{kJ} / \mathrm{kg}$

$\mathrm{h}_{4}=$ Specific enthalpy at the exit state, $\mathrm{kJ} / \mathrm{kg}$

4-1 Constant pressuer heat absorpsion in an evaporator

$$
\dot{Q}_{41}=\dot{Q}_{\text {Evap }}=\dot{m}_{R}\left(h_{1}-h_{4}\right)
$$

Where $\dot{Q}_{41}=\dot{Q}_{\text {Evap }}=$ The rate of heat absorption in an evaporator, $\mathrm{kW}$ 
$h_{4}=$ Specific enthalpy at the inlet state, $\mathrm{kJ} / \mathrm{kg}$

$h_{l}=$ Specific enthalpy at the exit state, $\mathrm{kJ} / \mathrm{kg}$

The Coefficient of Performance of a refrigeration machine is the ratio of energy removed at the evaporator to energy supplied to the compressor. Thus using the notation of Fig 1, we have the formula [4], [6]

$$
C O P_{R}=\left(h_{1}-h_{4}\right) /\left(h_{2}-h_{1}\right)
$$

\section{Equipment and Experiment}

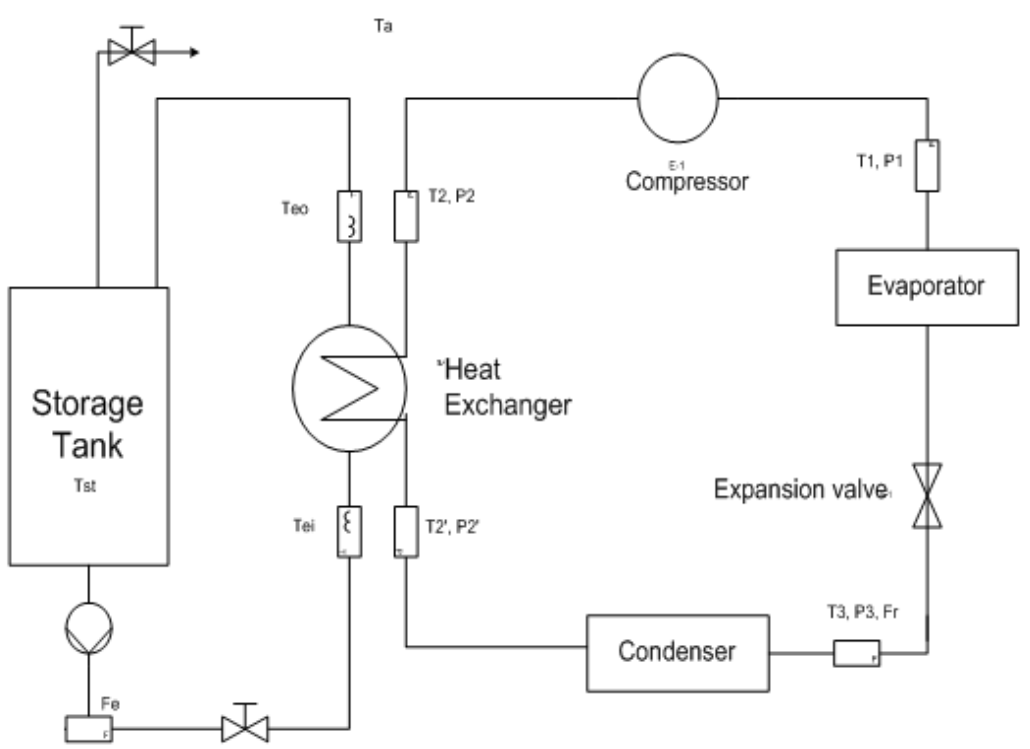

Fig. 2. The diagram of Hot Water Production system and data collecting position.

\subsection{Experiment Methods}

\section{The first section: The experiment of the operation of air conditioning system:}

Turn on the air-conditioner at $25^{\circ} \mathrm{C}$ in order to calculate the Coefficient of Performance (COP). Data is collected at each position every 5 minutes between 0-30 minutes.

The second section: The experiment of heat exchanger producing hot water with waste heat recovery from air conditioning:

1. Prepare the water in the tank at a top level of the system.

2. Open the valve which controls the water flowing into the heat exchanger.

3. Data is collected at each position every 5 minutes between 0-30 minutes.

4. Turn on the air-conditioner producing hot water from heat recovery. The water flow rate passes through the heat exchanger are 1, 3 and $5 \mathrm{~L} / \mathrm{min}$ respectively. Meanwhile, collecting data on various temperature of heat.

The accuracy of data collection should rely on repetition experiment, data comparison and ambient temperature. 

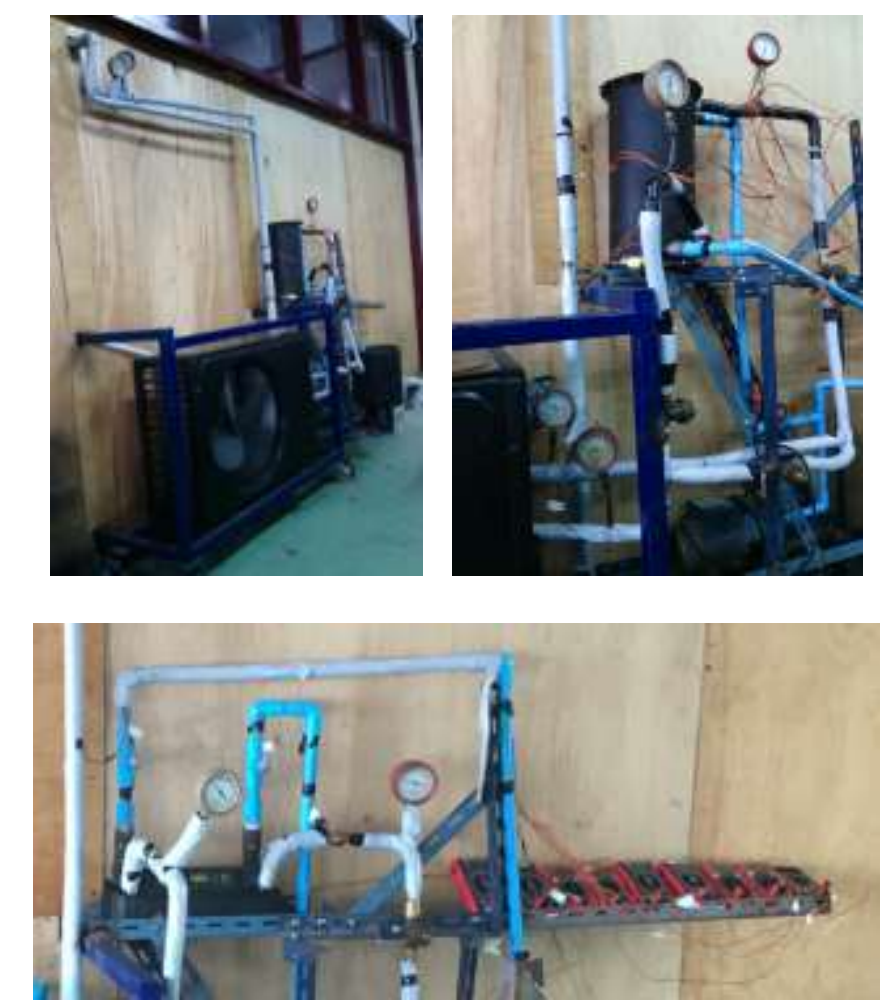

Fig.3. Condensing Unit, Pressure gage, Control Valve and Hot Water Tank

\section{Results and Discussion}

The experiment with hot water system is conducted in order to collect the data on various temperatures of heat exchanger producing hot water. The first section is the separate operation of air conditioning. The second section is Heat Exchanger producing hot water with waste heat recovery from air conditioner. The collected data of the two sections has been done between 0-30 minutes. Since this period boosts the system operation at its extreme capacity.

\section{Result of Testing}

The experiment with hot water system is separated into two sections. The first section is the split operation of air conditioning and the second section is Heat Exchanger producing hot water with waste heat recovery from air conditioning.

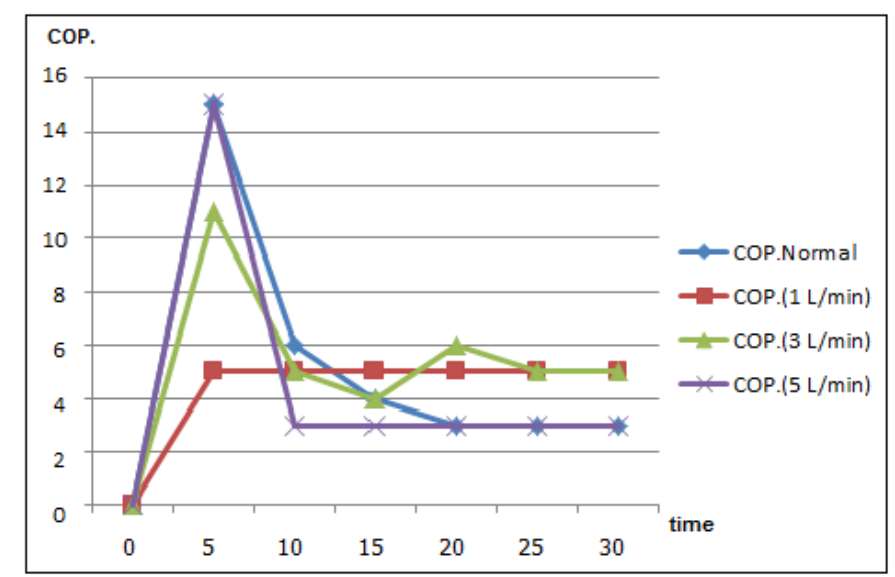

Fig. 4. A comparison of COP of the air-conditioner incorporated with heat exchanger to the normal system 


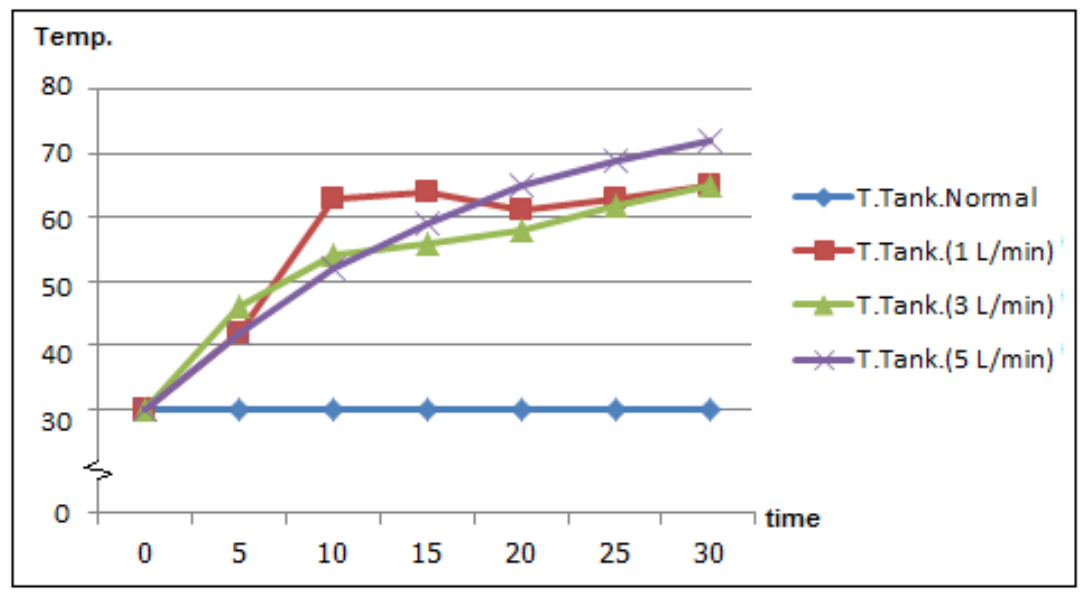

Fig. 5. A comparison of water temperature in the tank.

In comparison, the Coefficient of Performance (COP) of the air conditioner of the first experiment has constant value when it operates normally, The study reveals that the COP of the first section is 3 . Meanwhile, the COP of the second section are 5,5 and 3 respectively and The study reveals that the maximum temperature of hot water with waste heat recovery from air conditioning with 1, 3 and $5 \mathrm{~L} / \mathrm{min}$ of water flow rate are 65,65 and $72^{\circ} \mathrm{C}$ respectively. Since this period boosts the system operation at its extreme capacity.

The COP of the second experiment is higher than that of the first one since the water in the tank has lower temperature. It causes the refrigerant transfer heat from higher temperature medium to a lower temperature one before flowing into condenser and also takes much heat from the experiment room. The water flow rate in the second experiment is 1,3 and $5 \mathrm{~L} / \mathrm{min}$. When comparing with normal system air-conditioner, it can save $34 \%$, $38 \%$ and $-2 \%$ respectively.

\section{Conclusion}

The study reveals that the temperature of water is $30^{\circ} \mathrm{C}$. For the second experiment on Heat Exchanger producing hot water incorporated with waste heat recovery from air conditioning by using the heat exchanger with water inlet at 1,3 and $5 \mathrm{~L} / \mathrm{min}$ of flow rate and the temperature of hot water production are 65,65 and $72^{\circ} \mathrm{C}$ respectively. These temperature values in orderly are 35,35 and $42^{\circ} \mathrm{C}$ higher than temperature of water. Moreover, the Heat Exchanger producing hot water with waste heat recovery from air conditioning can save 34, 38 and $-2 \%$ of energy when comparing with normal operation system air-conditioner.

In summary, hot water incorporated with waste heat recovery from air conditioning is the most efficiency system among the two experiments since the maximum temperature of hot water is $65^{\circ} \mathrm{C}$ with $3 \mathrm{~L} / \mathrm{min}$ of water flow rate. The temperature of hot water produced by the Heat Exchanger with waste heat recovery from air conditioning is increased by $37^{\circ} \mathrm{C}$ which affected on increasing COP efficiency of normal system air-conditioner and can save $38 \%$ of energy.

\section{References}

[1] National Statistical Office, Office of the Prime Minister "A survey report on hospital and private clinic B.E. 2544"

[2] Final report on "A study of Hot Water Production from Solar Energy Technology" paper presented to Depart of Alternative Energy Development and Efficiency, Ministry of Energy by Energy and Environmental Engineering Center

[3] Kosart Thawichsri, et al., 2008, "Hot Water Production Using Waste Heat Recovery from Air Conditioning Incorporated with Solar Hot Water System" GMSARN International Conference on Sustainable Development: Issues and Prospect for the GMS, 12-14 Nov. 2008, Kunming, China.

[4] Cengel, Y. A., 1998, Thermodynamics, 3rd ed, New York: McGraw-Hill.

[5] Holman, J.P., 2001, Heat Transfer, 8th ed, Singapore: McGraw-Hill.

[6] Jones, W. P., 2001, Air Conditioning Engineering, 5th rd, Great Britain: Butterworth Heinemann. 